\title{
Capsule Commentary on Frank et al., Increased Hospital and Emergency Department Utilization by Individuals with Recent Criminal Justice Involvement: Results of a National Survey
}

\author{
Susannah L. Rose, PhD and Ruchi M. Sanghani, $M A^{2}$ \\ 'Department of Bioethics, Cleveland Clinic; Cleveland Clinic Lerner College of Medicine of Case Western Reserve University, Cleveland, OH, USA; \\ ${ }^{2}$ Department of Bioethics, Cleveland Clinic, Cleveland, OH, USA.
}

J Gen Intern Med 29(9): 1271

DOI: $10.1007 / \mathrm{s} 11606-014-2909-7$

(c) Society of General Internal Medicine 2014

$\mathrm{T}$ he relationship between low health status, such as health disorders, drug use, and epilepsy, and criminal activity is well documented. ${ }^{1,2}$ Persons within this population often are homeless, poor and/or have limited access to regular and primary care, and therefore seek emergency department (ED) and hospital services when their symptoms are more severe. ${ }^{2-4}$

In a large national sample $(\mathrm{n}=154,356)$, Frank et al. ${ }^{5}$ find that recent arrest is positively correlated with hospitalization and ED utilization, showing that $4.2 \%$ of the U.S. adult population has recent criminal justice involvement, yet accounts for $7.2 \%$ of hospital expenditures and $8.5 \%$ of ED expenditures. The authors call for improvements in the quality and access of care for criminal justice populations, which would not only improve their general health, but also reduce the costs associated with hospitalization and ED services.

While other non-health related correlates may still exist, ${ }^{1}$ health-related correlates can be partly addressed through healthcare policy and employment reforms. Health insurance options independent of employment, as part of the Patient Protection and Affordable Care Act, will help these individuals receive regular and primary healthcare, and lower the incidence of hospitalization and ED visits by those with criminal history.

Given that the authors cannot determine causality with the methods used, we also need to consider that health status may also be a potential driver of criminal activity, as suggested by Lee, Beaver and Wright, and others. ${ }^{1-3}$ Therefore, we also suggest that physician and hospital care provided through affordable or subsidized, independent insurance policies may help at-risk populations seek care prior to criminal involvement and arrest. Expanded health care access may have the potential to reduce the incidence of crime, particularly drug-related crime if rehabilitation options are available. Though this would require a financial investment from the general public, these services ultimately could reduce costs of emergency and long-term health services and for incarceration, while also improving public health and safety. We would add that other social reforms, including housing, social, community and income support are also needed to help improve the health of this population.

Corresponding Author: Susannah L. Rose, PhD; Department of Bioethics, Cleveland Clinic; Cleveland Clinic Lerner College of Medicine of Case Western Reserve University, 9500 Euclid Ave, Cleveland, $\mathrm{OH}$ 44195, USA (e-mail: roses2@ccf.org).

\section{REFERENCES}

1. Lee E, Beaver KM, Wright J. Handbook of Crime Correlates. Oxford: Academic Press; 2009.

2. James DJ, Glaze LE. Mental Health Problems of Prison and Jail Inmates. Bureau of Justice Statistics. 2006:NCJ 213600.

3. Ching-Chi H, Pugh MD. Poverty, income inequality, and violent crime: a meta-analysis of recent aggregate data studies. Criminal Justice Rev. 1993; 18:182-202.

4. Kangovi S, Barg FK, Carter T, Long JA, Shannon R, Grande D. Understanding why patients of low socioeconomic status prefer hospitals over ambulatory care. Health Affairs. 2013;32:1196-203.

5. Frank JW, Linder JA, Becker WC, Fiellin DA, Wang EA. Increased hospital and emergency department utilization by individuals with recent criminal justice involvement: results of a national survey. J Gen Intern Med. 2014. doi: 10.1007/s11606-014-2877-y.

Published online June 14, 2014 